Hans C. ten Berge

Hans C. ten Berge, dichter, prozaïst, poëzievertaler. Richtte in 1967 het tijdschrift Raster op. Bekroond met de Multatuliprijs (1987), Constantijn Huygensprijs (1996) en de P.C. Hooftprijs (2006). Publiceerde onder meer: Materia Prima, gedichten 1963-1993; Het Vertrapte Mysterie (2004) en Hollandse Sermoenen (2008), poëzie. Blauwbaards Ontwaken (2003), roman, Ontluisd Verleden (2006), vijf novellen. Literaire antropologie: Mythen en Fabels van Noordelijke Volken, 3 dln.(1987).

\title{
Niet bestelde brief aan een nomade
}

Dit dorp was een gelukkig dorp

de grote race der zielen ten hemel

werd wekelijks door vettige filmbeelden vertolkt

Lucebert, "Adieu tropenweelde"

De toendra is gebaat bij strenge vorst. Hogere temperaturen tasten de permafrost aan en maken de bodem onbegaanbaar week en modderig. In 1974 was het eind september al $-15^{\circ}$ Celsius overdag. Ofschoon de wind soms snijdend was en ongenadig, lag er sneeuw en was de Hudson Baai al goeddeels dichtgevroren. De toendra met haar prachtige witte poolvossen en schuwe kariboes, haar raven en veelvraten, haar sneeuwhoenders en hazen lag open voor treklustige bezoekers en bewoners. In Parijs echter viel onophoudelijk regen en had Breyten het werk aan zijn poëtisch dagboek Soos die So stopgezet. Hij zou een jaar lang elke dag een vers noteren. "Alle skrywe is gesprek aanknoop/jy praat met iemand,/ trobbel is dat niemand nie antwoord nie" noteert hij op 13 februari 1974. In september gaf hij er dan ook de brui aan - om het werk pas eind 1988 te voltooien.

Vanuit een dorp aan de Hudson Baai begon ik inmiddels brieven te verzenden om in de immense stilte een begin van een gesprek "aan (te) knoop." Weinig kon ik vermoeden dat de aan Breyten gerichte brief nooit zou aankomen, en dus ook niet beantwoord kon worden. Na terugkeer uit Canada in de zomer van 1975 bleek telefonisch contact met de rue Malebranche in Parijs eveneens te mislukken. De telefoon werd wekenlang niet opgenomen. Kort daarop kwam het alarmerend bericht van Breytens arrestatie op het vliegveld van Johannesburg. De feiten en omstandigheden zijn bekend, en doen hier niet terzake. In plaats van een ontmoeting in Parijs of Amsterdam volgden jaren van stilte - maar ook van veel rumoer, geruchten en geroddel in de pers. De vriendschap bleef onaangetast, al kon die alleen langs omwegen worden bevestigd. Op verzoek van het tijdschrift $D e$ Gids schreef ik die zomer een essay over Breytens werk onder de titel: "Dichter zonder taal, schilder zonder ogen" 
- waarin de monddode dichter en de geblinddoekte schilder tot één gestalte werden versmolten. Het stuk werd later gevolgd door een lang gedicht getiteld “De Hartlaubmeeuw" (over de meeuwenkolonie op Robbeneiland, opgedragen aan B.B. 'doing nine years in the cooler'), en een reeks korte verzen waaruit diepe bezorgdheid en bittere weemoed sprak. Een strofe daaruit gaat als volgt:

Hoeveel maanden sinds je wegging

- "Wellington toe met lang bene" -

en heimwee ruilde voor het bordienghuis

met kelders

waar de vaderen automatische violen stemmen

en het puik van kaapse kelen a-capella psalmen zingt ...

Lang nadat hij tot bajesklant, of 'tronkvoël', gepromoveerd was ontving ik in januari 1980 een volgekrabbelde kaart van Breyten uit de zuidafrikaanse gevangenis, een gebeurtenis die behalve ontroering ook een 'ongepast' en 'slechtzittend' sonnet uitlokte. In literair Nederland hielden enkele spraakmakende auteurs zich in die tijd onledig met ruzies en gênant gescheld dat op een primitieve territoriumstrijd leek te berusten. Het was raadzaam die volstrekt te negeren om de eigen onbevangenheid niet te corrumperen.

Terwijl ik lees

hoe de schrijvende onderwereld van dit land

zich frenetiek met beuzelarijen

op de been houdt,

gaat de poëzie als altijd schuil

in lege kamers en jouw kale cel.

Schemerlicht en water tot de winterdijk.

Een meisje rijdt voorbij op een wit paard.

Na vier jaar boordevol stilte

brengt de post een groet

uit de gevangenis

en zitten wij stil

om de tafel

een weerzien te vieren.

25.I.80 / 4.30 p.m.

De wereld, de omstandigheden, en onze levens zijn sindsdien ingrijpend veranderd, niet altijd ten kwade, zelfs al blijft het perfide vernuft van de mens op tal van plaatsen 
onheil aanrichten. Zoals jij, Breyten, het vertrouwde Parijs afwisselend voor Spanje, Senegal, New York en Zuid-Afrika verruilt, zo heb ik Amsterdam al lang geleden verlaten. Amsterdam heeft weinig toekomst, de stad is de braakbal van een zieke uil, een grauw toeristennest, een stad met dorpse allures die zichzelf overschat en (soms letterlijk) ondermijnt, en die haar rijkdom aan kunst voor jaren ontoegankelijk heeft gemaakt door de grote musea tegelijkertijd wegens verbouwingen te sluiten. Bovendien is Galerie Espace, jouw schilderkunstige steun en toeverlaat, van de aardbodem verdwenen. Maar geen nood: zodra de zeespiegel gaat stijgen, spoelt de hele zaak in een keer weg, en sluit de rest van Nederland zich vreedzaam aan bij Duitsland. De grenzen in Europa zijn immers al opgeheven.

Terwijl jij over de wereld zwerft en op wonderlijke, soms onbegrijpelijke manier je werk in stand weet te houden, reis ik nu meer in de verbeelding dan in werkelijkheid. Voor jouw leefwijze is zeer veel kracht vereist, meer dan buitenstaanders met voldoende kapitaal en veilige pensioenen kunnen vermoeden. We zien elkaar slechts zelden, eigenlijk bijna nooit. Maar de vriendschap berust op gevoelens die onveranderd zijn gebleven: hoe kan het anders tussen een knokige Fries uit Noord-Holland en een koppige Boer uit Bonnievale die ondanks alles hun soepelheid en open geest willen behouden. Nu wij beiden zeventig zijn, of worden, is het tijd de brief uit 1974 langs deze omweg te bezorgen. Misschien is hij je ooit, bij toeval, toch onder ogen gekomen in een boek, De Beren van Churchill, dat tijdens jouw verblijf in de tronk werd uitgebracht. Maar ach, wat doet het ertoe. Met een blik op de kosmos doen wij er zelf nauwelijks toe.

Mocht je afwezig zijn, dan speld ik het bundeltje papieren op de voorhang van je tent. Je zult het vinden als je mompelend, op rode schoenen, diep in de nacht, "onder koel tente van die Sahara", vermomd als toeareg thuiskomt, waar een verrassend elegante Lotusdame, op oosterse kleden gezeten, de olielamp brandende houdt.

In een sombere wereld drinken wij vrolijk een glas op vriendschap en gezondheid voor nu en in de toekomst. Bottoms up! En nog vele jaren!

Rankin Inlet, NWT, 11 november 1974. Beste Breyten - In Nederland gaan de kinderen nu zingend langs de huizen met hun lampions en tassen en plastic zakken, waar de buitgemaakte appels, koeken, toffees, lollies, wijn- en toverballen in verdwijnen. "Slegte kos", mompel je goedmoedig in dat verre Parijs. Maar het is Sint Maarten en ik hoor ze schreeuwen in straten en portieken... Hier woont een rijk man, die veel geven kan... Gestommel, gegiechel, gescheld op de trappen. Groepen die elkaar tegenkomen en van de traptreden duwen. Per ongeluk expres meneer. Gelach, kleine geniepigheden, verborgen opstoppers. Kleuterdrama's van verkoolde draagstokjes en lampions in lichterlaaie. En als je niet gauw genoeg opendoet: 
Sintere Maarten de deur zit vast,

geef die kerel op ze bast,

geef dat wijf een dikke zoen,

dan zal ze de deur wel opendoen!

Is het een verregende Sint Maarten? Op de dag van mijn vertrek uit Amsterdam begon het te stortregenen en ik maak uit de berichten op, dat het - ook bij jullie sindsdien niet meer droog is geweest. Halfverrotte aardappels worden door het leger uit de vette Zeeuwse klei omhoog gebaggerd. Wat een onderwerp! Maar toch, als het maar lang genoeg regent kan het je voorgoed aan de drank en de flipperkast brengen. Een reden te meer om spoedig eens in dit heldere land op bezoek te komen, vooral nu de lucht smetteloos strak staat en knapperig van kou is.

Zoals ik al eens schreef zijn de missionerende paters in de North-West Territories overwegend franstalig. Ze zaten al tientallen jaren in plaatsjes als Chesterfield Inlet, Eskimo Point en Fort Churchill, maar zijn pas in 1956, tegelijk met de nikkeldelvers, naar Kangerdlinerk - oftewel Rankin Inlet - gekomen. Kangerdlinerk is een jong dorp, waar een nikkelmijn tijdelijk voorspoed en ontwrichting bracht. $\mathrm{Nu}$ is de mijn al weer dicht, zijn de inheemse, omgeschoolde mijnwerkers de jacht op zeeijs en toendra ontwend, en gingen de bazen uit het zuiden er stilletjes vandoor. De paters werden al spoedig gevolgd door anglicanen, en leden van een soort pinksterbeweging. Je reinste zielenstrijd dus, met als inzet een paar honderd mensen die van hun gezond niet wisten en nergens om gevraagd hadden. Bij de katholieken viel het meeste te halen en werd het mooiste gezongen, zodat zij de wedstrijd wonnen. Vandaar dat men Isaac, Pierre of Elisabeth heet in plaats van Mondjevol, De Wijsvinger of Meeuwenei, verbeeldingrijke namen die men aan de kinderen, kort na hun geboorte, geeft. Nu wordt alleen de doopnaam geregistreerd. De andere wordt afgewezen of genegeerd. Zijn de mensen echter onder elkaar, dan gebruikt men de naam die meteen na de geboorte werd bedacht.

De wedijver tussen de blanke broeders in God heeft een vermakelijke kant. De katholieke missionarissen noemen de niet-roomse zendelingen "de oppositie". Om de oecumenische en christendemocratische eenheidsbeweging niet te beschamen wordt deze term alleen binnenshuis gebezigd. Er doen zich komische incidenten voor, zoals onlangs in Eskimo Point, waar twee afgezanten van God een daverende ruzie uitvochten over het lijk van een vrouw dat tussen twee christelijke begraafplaatsen had moeten kiezen, maar door omstandigheden geen stom woord meer uitbracht. Het herinnerde de mensen aan een voorval uit de jaren twintig in dezelfde nederzetting. Een jonge anglicaanse zendeling, die pas kort in het gebied was, ontdekte een katholiek amulet om de hals van een man die hij tot zíjn aanhangers rekende. Hij rukte het kettinkje met medaillon van's mans nek, rende ermee naar de katholieke missiepost, smeet het daar weg en stampte het woedend de grond in. 
Niettemin heeft er altijd een stilzwijgende overeenkomst bestaan die inhield, dat degene die als eerste kontakt met een groep had gelegd en de namen had opgeschreven een religieus wingewest had afgebakend, als gold het een olie- of goudclaim. Het is niet ondenkbaar dat men ook katholieke, anglicaanse of methodistische urine sprenkelde om ieders domein op wolfachtige wijze te markeren. Jammer dat de heidense bewoners deze afspraak dikwijls doorkruisten door heimelijk lid te worden van meer dan éen genootschap. De zondaren namen het zekere voor het onzekere en lieten zich meteen maar inschrijven voor alle reizen naar de eeuwigheid.

De officiële voertaal is Engels, maar de taal van het land heet Inoettitoet (geschreven als: inuktitut). Het Engels wordt beschouwd als een wilde taal waarmee je alleen in grove zin kunt aangeven wat je bedoelt of wat jou bezielt. Het is de taal van de bazen uit Yellowknife en Ottawa, van de nijvere druktemakers die olie en gas uit gaten in de grond proberen te halen in de stellige verwachting dat de vlakke toendra in een gouden berg verandert. Het is ook de taal waarin je om steun vraagt aan langzame klerken die cheques voor behoeftigen uitschrijven. Het Frans heet taktaktoettitoet - "dat wat zo snel gesproken wordt dat je het niet kunt verstaan." De enige taal waarin je je behaaglijk nestelen kunt is de eigen taal. Inoettitoet dus. Alleen al om die reden, maar ook omdat ik zo kort in dit dorp kan verblijven, zal ik slechts oppervlakkig kunnen kennisnemen van wat zich in deze gemeenschap afspeelt. Het is de buitenkant waar ik even aan mag ruiken en raken. Een grondige kennis van de werkelijke cultuur kan alleen met een grondige kennis van de taal verworven worden.

Het taalprobleem krijgt overigens veel te weinig aandacht. Op de scholen wordt Engels gepraat en spreekt men de kinderen alleen met de doopnamen aan. Het is zoiets als Nederlandse kleuters in het Spaans onderwijzen, en ze hardnekkig anders noemen dan ze heten. De zoon van Isaakie, een twaalfjarig jongetje, heeft niet zomaar een eind aan zijn leven gemaakt.

De bureaus vertonen hetzelfde beeld. De weinige ambtenaren die wel bereid zijn de Eskimotaal te leren, worden door hun chefs wantrouwend bekeken, omdat ze zich teveel met de belangen van de oorspronkelijke bevolking zouden kunnen identificeren. Overplaatsen of terugroepen blijkt ook in dit geval een doeltreffende, diplomatieke methode om belangstelling, inleving of gevoelens van sympathie te blokkeren. Een aantal jaren geleden merkte het toenmalige hoofd van de afdeling Onderwijs van het Department of Northern Affairs op, dat het vanuit politiek oogpunt voor de Canadese regering noodzakelijk was de uitroeiing van de Eskimotaal ("the elimination of the Eskimo language") te voltooien. Hij voegde eraan toe dat deze taal alleen museumwaarde had, dat ze van zeer gering belang was en de oplossing van sociale problemen in de weg stond. Een echte deskundige dus met een warm hart.

Hoewel de verschillen groot zijn, zullen je enkele overeenkomsten met de situatie in Zuid-Afrika niet ontgaan. Wat hier door enkelingen of een groepje dikhuiden wordt verkondigd, is in jouw land helaas tot systeem verheven. 
De ouders kunnen de kinderen steeds minder de baas, omdat op traditionele verzoeken of aanwijzingen niet meer gereageerd wordt. Het is tragi-komisch uit de monden van Eskimovrouwen uitroepen te horen als: "Je moet een lief kind zijn, want als je je slecht blijft gedragen geef ik je aan de districts-administrateur!" Of: "Als je niet lief bent zal de man van de regering je pakken!"

Hoe je als blanke een boze, zwarte Piet wordt.

Wat de katholieke missionarissen altijd gesierd en tot voordeel gestrekt heeft, is hun bereidheid overal de taal van het land te spreken - en vloeiend te spreken - en de plaatselijke bevolking met respect tegemoet te treden. Hun houding lijkt me historisch verankerd in een soort wetgeving die al in 1539 door Francisco de Vitoria in Salamanca werd ontwikkeld. Zijn veelvuldige kontakten met monniken die op de Caribische eilanden, in het pas veroverde Nieuw-Spanje en in het voormalige Inca-rijk werkten, leidden tot een scherpe veroordeling van het wangedrag der Conquistadores, die de Indiaanse bevolking mishandelden, uitzogen en op brute wijze schoffeerden. Op tal van gronden - waaronder die van een afwijkend sexueel gedrag - rekende men de inheemse bevolking niet tot het menselijk ras. De veroveraars werden in het bijzonder gefascineerd door de sodomitische gedragingen van de barbaarse inboorlingen. Sodomie, zo meende men, had de verspreiding van syfilis tot gevolg. Want hield het aantal waarnemingen van sodomie niet gelijke tred met de opmars van de syfilis in het zojuist ontdekte werelddeel? Wie als Indiaan een druiper opliep werd op passende wijze gestraft voor sexueel wangedrag, vonden de Spanjaarden. Dat de syfilis, evenals de Spaanse kraag, een geschenk uit Europa was, werd pas later onderkend.

Het voor de hand liggende gevolg van dit alles was, dat men met Indianen mocht doen wat men wilde. Dat gebeurde aanvankelijk ook, totdat de Kerk zich in de affaire mengde onder invloed van De Vitoria's verlichte ideeën. Aan de hand van diens beroemd geworden colleges over de positie van de Amerikaanse Indianen deed zij een uitspraak ten gunste van de autochtone bewoners van de veroverde gebiedsdelen. Hun vermogen tot denken (de rationele aard van de mens) en hun menselijke natuur mochten voortaan niet meer in twijfel worden getrokken. Daarmee was hun voortbestaan, hoe arm en berooid ook, gewaarborgd, en werd slavernij, op papier, afgewezen. Gezien de schokkende ontwikkelingen in de zestiende eeuw, gezien ook de toenmalige verhoudingen en de altijd benarde positie van verlichte geesten, mogen wij over zo'n uitspraak niet al te schamper denken. Francisco de Vitoria heeft echter niet (kunnen) voorzien dat de handel in Afrikaanse slaven mede hierdoor kon ontstaan. Er moest een nieuwe "arbeidsreserve" (wat een cynisch woord) worden aangeboord.

Een pikante formulering in de vele conclusies die De Vitoria's colleges rijk waren, is de volgende: Hoe wettig het gezag van een christenprins over de heidenen ook mag wezen, hij kan hen niet meedogenlozer onderdrukken dan zijn christelijke onderdanen, hij kan hun geen hogere belastingen opleggen, zich aan vrijheidsberoving overgeven of enige daarop gelijkende onderdrukkingsmethode hanteren. 
Francisco, een Bask van geboorte, ging veel verder dan de paus en de Spaanse kroon, in de persoon van Karel V, konden toestaan. Ofschoon ook hij "afwijkend gedrag" op sexueel en aanverwant gebied verwerpelijk vond, weigerde hij desondanks de jurisdictie van keizer of paus over de Amerikaanse Indianen te erkennen, of die zelfs maar te rechtvaardigen op grond van "onnatuurlijke zonden of irrationeel gedrag" van de bevolking. Integendeel, hij wenste het gezag van de inheemse leiders erkend te zien.

De Nederlandse historicus Cornelius de Pauw presteerde het om ruim tweehonderd jaar later de stelling te verdedigen (in Recherches philosophiques sur les Americains van 1769), dat de Indianen fysiek zowel als geestelijk minderwaardig waren aan de Europeanen. We hoeven ons daarover niet bijzonder op te winden, omdat je dan vandaag de dag nog steeds handenvol werk zou hebben, ook aan allerlei auteurs van Nederduitse, Nederlandse of wat voor herkomst ook. (De veelgelezen Van het Reve bij voorbeeld staat borg voor onverhuld racistische opvattingen, die op zogenaamd grappige toon worden gedebiteerd.) Het tekent evenwel de zelfgenoegzame en geborneerde levenshouding van de geleerde Amsterdammer die De Pauw is geweest.

Verskoning vir hierdie ompad. Die was nodig om te laten zien waarom de katholieke missionarissen in hun bekeringsdrift toch een andere houding aan de dag legden dan vele van hun christelijke concurrenten. Het zou de libertijn in mij onwaardig zijn alleen de negatieve kanten van hun aanwezigheid te belichten. Nu vond ik in de bibliotheek van het verlaten Arctisch Centrum waar ik tijdelijk woon, een opmerkelijke notitie van de hand van de afwezige directeur, Bob Williamson. Ze werpt enig licht op deze zaak voor zover de Eskimo's in het geding zijn. Er staat het volgende:

Veruit de hoogste graad van morele druk en buitensporig emotionele vijandigheid ten aanzien van traditionele geloofsopvattingen, folklore en gebruiken werd door de anglicaanse zendelingen aan de dag gelegd. De oude volksliederen, de oude volksverhalen, de trommeldansen, en zelfs het snijden van beeldjes met traditionale voorstellingen, werden zeer rigoureus onderdrukt, vooral in Baker Lake. Zulke traditionalistische culturele verschijnselen werden in de hoofden van de zendelingen geassocieerd met heidendom, en derhalve, per definitie, gelijkgesteld aan Zonde. Hoewel de katholieke missionarissen een geloofssysteem inprentten dat nauwelijks minder ambivalenties, spanningen en angsten opriep, hebben zij de eskimowaarden, de taal en folklore in veel grotere mate gerespecteerd. In feite is veel van het nu beschikbare folkloristische materiaal door de katholieke missionarissen opgetekend en verzameld. Het is eveneens tekenend dat de missionarissen zonder uitzonderling een veel hogere graad van bekwaamheid in de eskimotaal hebben verworven dan welke anglicaanse zendeling ook die in dit deel van het poolgebied geweest is.

Nu ben ik uitgeput en jij waarschijnlijk ook! Alles van die beste, en vergeet dat oude opschrift niet: "Ons lewe tot ons sterf." Ik zie je dus nog? 